
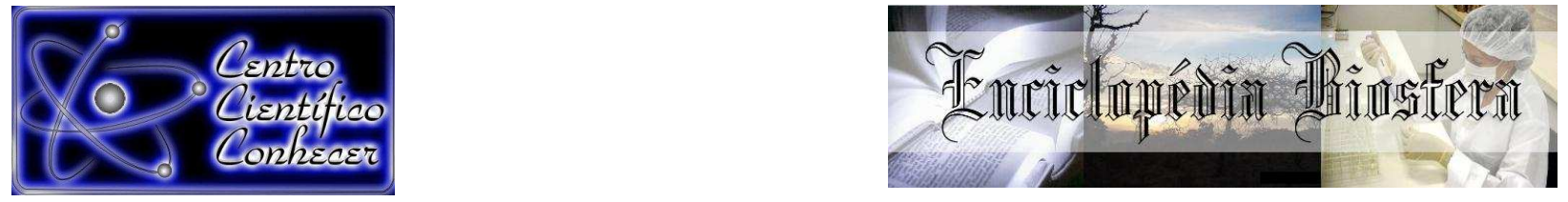

\title{
APLASIA UNILATERAL DE CORNO UTERINO ASSOCIADA À PIOMETRA E CISTO PAROVARIANO UNILATERAL EM GATA: RELATO DE CASO
}

Luis Fernando Mercês Chaves Silva ${ }^{1}$, Endrigo Adonis Braga de Araujo ${ }^{1}$, Sidnei Nunes de Oliveira ${ }^{1}$, Felipe Morales Dalanezi ${ }^{1}$, Catarina Borges Cardosoํㅜ, Fabíola Soares Zahn ${ }^{1}$, Nereu Carlos Prestes ${ }^{1}$.

${ }^{1}$ Departamento de Reprodução Animal e Radiologia Veterinária, Universidade Estadual Paulista "Júlio de Mesquita Filho" Unesp - Botucatu, SP, Brasil. E-mail: luisfernando.mchaves@gmail.com

Recebido em: 08/09/2015 - Aprovado em: 14/11/2015 - Publicado em: 01/12/2015 DOI: http://dx.doi.org/10.18677/Enciclopedia_Biosfera_2015_082

\section{RESUMO}

Nos felinos a ovulação é induzida por meio da cópula, portanto a espécie não é tão sujeita a frequentes elevações nas concentrações de progesterona. Diante disto a ocorrência de piometra geralmente está associada à administração indiscriminada de progestágenos. As anomalias congênitas do útero de felinos são raras, dentre elas a aplasia segmentar está associada à falha no desenvolvimento dos ductos paramesonéfricos. Tendo em vista a baixa incidência dessas afecções na espécie, objetivou-se relatar um caso de aplasia unilateral em corno uterino associado à piometra em uma gata com 15 anos de idade. À anamnese, o proprietário relatou apatia, anorexia, adipsia e secreção vaginal há 10 dias, além da administração consecutiva de contraceptivo há 15 anos (desde o primeiro cio). As alterações clínicas observadas foram presença de secreção vulvar mucopurulenta, hipertermia $\left(40,2^{\circ} \mathrm{C}\right)$, apatia, anorexia e dilatação abdominal evidente. Ao exame ultrassonográfico da cavidade abdominal, constatou-se presença de conteúdo uterino, representado por regiões anecóicas bem evidentes, características dos achados ultrassonográficos de piometra. Os valores hematológicos revelaram leucocitose grave por neutrofilia com desvio à esquerda; no exame, bioquímico foi observado alteração das enzimas hepáticas, renais, hiperglobulinemia e hiperproteinemia, condizentes com o quadro de piometra. Diante do quadro clínico, procedeu-se laparotomia em caráter emergencial e verificou-se que apenas um dos cornos uterinos apresentava conteúdo e aplasia do corno contralateral, além disto o ovário ipsilateral ao corno com conteúdo apresentava cisto parovariano. Após dez dias da realização da ovariosalpingohisterectomia a paciente retornou, para reavaliação e retirada dos pontos, com a saúde restabelecida.

PALAVRAS CHAVE: Afecções reprodutivas, felinos, formações císticas, infecção uterina, patologia congênita.

\section{UNILATERAL APLASIA OF UTERINE HORNE ASSOCIATED WITH PYOMETRA AND UNILATERAL PARAOVARIAN CYST IN CAT: CASE REPORT}

\begin{abstract}
Ovulation in cats is induced by copulation, so this species is not frequently subject to increases in progesterone concentrations. The occurrence of pyometra is usually
\end{abstract}


associated with indiscriminate administration of progestogens. Congenital anomalies of the uterus in cats are rare, among them segmental aplasia is associated with failure to develop the paramesonephric ducts. Given the low incidence of these diseases in the species, the authors aimed to report a case of unilateral aplasia of uterine horn associated with pyometra in a 15 years old cat. In the clinical history, the owner reported apathy, anorexia, adipsia and vaginal discharge 10 days ago, in addition to contraceptive management for 15 years (from the first heat). The clinical changes observed were the presence of purulent vulval discharge, hyperthermia $\left(40.2^{\circ} \mathrm{C}\right)$, apathy, anorexia and apparent abdominal elargement. The ultrasound examination of the abdomen evidenced the presence of uterine contents, represented by anechoic regions, consistent with sonographic findings of pyometra. Complete blood count revealed severe leukocytosis by neutrophilia with left shift. Serum biochemistry revealed alteration in liver and kidney enzymes, hyperglobulinemia and hyperproteinemia, consistent with pyometra. Based on the clinical fidings, laparotomy was carried out on an emergency basis and it was observed that only one of the uterine horns was enlarged and the contralateral horn was absent, in addition, the ovary ipsilateral to the horn with content presented Parovarian cyst. Ten days after the completion of ovariosalpingohisterectomy, the patient returned with restored health and sutures were removed.

KEYWORDS: Reproductive disorders, cats, cystic formations, uterine infection, congenital disease.

\section{INTRODUÇÃO}

Dentre as afecções que acometem o trato reprodutivo dos carnívoros domésticos, a piometra é uma das mais relatadas e de maior gravidade, sendo caracterizada pela ocorrência de inflamação no útero resultando em acúmulo de material purulento no ambiente uterino (DAVIDSON, 2015). Apresenta-se como piometra aberta, quando há abertura do óstio cervical, manifestando como principal sinal clínico a eliminação frequente de conteúdo purulento ou piometra fechada, quando não há abertura da cérvix (STONE, 2007).

A ocorrência da piometra depende de um evento conhecido como hiperplasia endometrial cística, resultante da ação estrogênica durante o estro, gerando desenvolvimento endometrial e abertura da cérvix, seguido da ação progestacional durante o diestro, promovendo estímulo do crescimento e atividade das glândulas endometriais com consequente acúmulo de fluídos e redução da imunidade do animal, fatores que em conjunto criam um ambiente uterino favorável a proliferação de microorganismos patogênicos, dentre eles a Escherichia coli, bactéria mais frequentemente envolvida (DAVIDSON, 2015).

Esta enfermidade é geralmente relacionada a animais de idade avançada e mais comum em cadelas do que em gatas, devido ao fato de que nos felinos a ovulação é induzida por meio da cópula, reduzindo a frequência de exposição ao aumento nos níveis de progesterona por reduzida incidência de ovulação sem que haja fertilização. Portanto, nos felinos, a etiologia está ligada quase que exclusivamente à administração inadvertida de fármacos contraceptivos à base de progestágenos assim como administração de fármacos similares para tratamento de algumas moléstias cutâneas (FELDMAN, 1989; AIELLO \& MAYS, 2001; DAVIDSON, 2015).

O desenvolvimento incompleto dos ductos paramesonéfricos durante a vida embrionária pode se manifestar como uma série de anomalias congênitas em tubas uterinas, corpo e cornos uterinos e parte cranial da vagina (SCHULMANA \& 
BOLTONB, 1997; OH et al., 2005; CHANG et al., 2008; GRADELA et al., 2013; AGUIRRA et al., 2014). Um exemplo é a aplasia de corno uterino, condição que pode acometer ambos os cornos (aplasia uterina total), somente um corno (aplasia uterina parcial, unilateral ou útero unicorno), ou uma parte de um corno (aplasia segmentar) (VINCE et al., 2011). De acordo com CHANG et al., (2008), a maioria das anomalias de desenvolvimento do trato reprodutivo envolvem os cornos uterinos.

Segundo AGUIRRA (2014), aplasias de segmentos do sistema reprodutivo podem estar presentes em cães e gatos de qualquer raça. Muitas vezes o diagnóstico destas enfermidades consiste de um achado acidental em laparotomias exploratórias, ovariosalpingohisterectomias ou exames post mortem (CHANG et al., 2008; AGUIRRA et al., 2014), uma vez que dificilmente sinais clínicos estão presentes (CHANG et al., 2008).

$\mathrm{Na}$ maioria dos casos os ovários estão funcionais e morfologicamente normais, o que explica a atividade cíclica normal em fêmeas acometidas por aplasia uterina, e é justificado pela diferente origem embriológica dos ovários (ALMEIDA et al., 2010; MCINTYRE et al., 2010; VINCE et al., 2011; GRADELA et al., 2013; AGUIRRA et al., 2014). Exceto em casos de aplasia bilateral, a fertilidade não é afetada, sendo que um menor número de filhotes pode ser observado (VINCE et al., 2011; GRADELA, 2013).

A aplasia uterina pode estar associada à hidrometra ( $\mathrm{OH}$ et al., 2005), complexo endometrial cístico/ piometra (SCHULMANA E BOLTONB, 1997), condições hermafroditas ou ainda à agenesia renal ipsilateral, em decorrência do desenvolvimento interligado dos sistemas reprodutivo e urinário (CHANG et al., 2008; MCINTYRE, 2010).

A ocorrência de cistos parovarianos é rara entre os animais domésticos, sendo os cistos foliculares os mais relatados (KIM et al., 2011). Os cistos parovarianos são provenientes de remanescentes de mesotélio, ductos paramesonéfricos ou ductos mesonéfricos e são encontrados em partes do mesovário, ligamento situado entre ovário e tuba uterina (KIM et al., 2011; JAIN et al., 2012; KATKE, 2013).

$\mathrm{Na}$ medicina veterinária, foram descritos relatos de acometimento de cistos parovarianos em cadelas (KIM et al., 2011; JAIN et al., 2012) e em macaco Reshus, no qual os cistos eram associados a endometriose (GREEN et al., 1999), existindo pouca descrição desta afecção para a espécie felina. Em humanos, cistos parovarianos constituem aproximadamente $10 \%$ das patologias das estruturas anatômicas ligadas ao útero (KATKE, 2013). Devido à baixa incidência, os sinais clínicos inerentes aos cistos parovarianos não estão elucidados (KIM et al., 2011; JAIN et al., 2012). Em humanos, as principais complicações são as torções, hemorragias e rupturas (KATKE, 2013).

Usualmente, o diagnóstico se dá acidentalmente em ovariohisterectomias eletivas ou não, no caso de alterações reprodutivas concomitantes, como piometra e neoplasias (KIM et al., 2011; JAIN et al., 2012). Ao exame ultrassonográfico, podese observar presença de estrutura cística preenchida por conteúdo anecóico e com paredes delgadas separado do ovário ipsilateral, o qual se encontra sem alteração morfológica (KIM et al., 2011). Este relato tem por objetivo descrever o caso de uma gata com aplasia unilateral de corno uterino esquerdo, associada a piometra e cisto parovariano em ovário direito. 


\section{RELATO DE CASO}

Foi atendida no Ambulatório de Pequenos Animais do Departamento de Reprodução Animal e Radiologia Veterinária da Universidade Estadual Paulista "Júlio de Mesquita Filho" Unesp - Botucatu - SP, uma gata sem raça definida com 15 anos de idade, pesando 8,2 quilos e apresentando considerável distensão abdominal e apatia. A anamnese, a proprietária relatou como queixas principais a perda de apetite e a redução da ingestão de água por parte do paciente assim como eliminação de secreção vaginal com odor fétido há 10 dias. Além disso, a proprietária revelou ter administrado acetato de medroxiprogesterona à gata durante 15 anos visando interromper a manifestação do cio. Ao exame físico, notou-se mucosas hipocoradas, desidratação, frequência cardíaca em 160 bpm, frequência respiratória dentro dos padrões para a espécie $(16 \mathrm{mpm})$ e temperatura retal aumentada $\left(40,2^{\circ} \mathrm{C}\right)$.

Ao exame clínico observou-se presença de secreção vulvar mucopurulenta e intensa distensão abdominal (Figura 1). Ao exame ultrassonográfico da cavidade abdominal (Figura 2) constatou-se áreas lobuladas com regiões anecóicas bem evidentes. Efetuou-se colheita de sangue, para realização de hemograma e exame bioquímico, sendo que os achados hematológicos revelaram leucocitose por neutrofilia com desvio à esquerda $\left(50,4 \times 10^{3} \mu / L\right)$ e presença de neutrófilos tóxicos, a série vermelha indicou discreto aumento de proteínas totais $(9 \mathrm{~g} / \mathrm{dL})$, sem mais alterações significativas. Ao exame bioquímico, observou-se aumento nos níveis de uréia (75 mg/dL), elevação de gama glutamil transferase - GGT $(7,1 \mathrm{UI} / \mathrm{L})$, e aumento de proteínas totais $(8,8 \mathrm{~g} / \mathrm{dL})$ principalmente por hiperglobulinemia $(6,1$ $\mathrm{g} / \mathrm{dL})$.

Com o diagnóstico inicial de piometra aberta, o animal foi submetido à ováriohisterectomia $(\mathrm{OSH})$ de caráter emergencial. As medicações pré-anestésicas utilizadas foram: Fentanil $(0,002 \mathrm{mg} / \mathrm{kg})$ e Midazolam $(0,2 \mathrm{mg} / \mathrm{kg})$; a indução anestésica foi realizada com Propofol (5 mg/kg, dose-efeito); a manutenção do plano anestésico foi realizada com Isofluorano. Durante todo o procedimento o animal recebeu solução de Ringer com Lactato e seus parâmetros se mantiveram estáveis no decurso da cirurgia.

A laparotomia foi realizada através da linha alba, e a exposição do trato reprodutivo constatou-se a presença de apenas um corno uterino preenchido por conteúdo, o outro corno apresentava-se ausente (Figura 3). O ovário ipsilateral ao corno com material mucopurulento continha um cisto parovariano. A ovariosalpingohisterectomia foi realizada para tratamento da piometra.

O diagnóstico definitivo foi aplasia segmentar de corno uterino esquerdo, associado a piometra em corno uterino direito e cisto parovariano em mesovário direito. O tratamento domiciliar foi realizado com Meloxicam $(0,1 \mathrm{mg} / \mathrm{kg})$ e Cefalexina (30 mg/kg), além de limpeza da ferida cirúrgica e aplicação de iodo tópico. Dez dias de pós-operatório, os pontos foram retirados e a paciente reavaliada, apresentandose já com a saúde restabelecida, apta a receber alta médica (Figura 4).

\section{DISCUSSÃO}

A piometra é uma afecção que acomete fêmeas em idades avançadas, com uma média na espécie felina de seis anos (HAGMAN et al., 2009) em fase de diestro ou início de anestro (DAVIDSON, 2015). A doença se dá devido a repetida estimulação hormonal no útero por diversos ciclos e às terapias hormonais visando ação contraceptiva, sendo a segunda a causa mais demonstrada em gatas (EVANGELISTA et al., 2011; DAVIDSON, 2015). Em consonância com estes dados, 
a gata deste relato possuía 15 anos de idade e havia recebido anticoncepcionais de forma indiscriminada por tempo prolongado.

Os principais sinais clínicos observados foram apatia, distensão abdominal, oligodipsia, desidratação e secreção vaginal fétida, reiterando os já descritos pela literatura. Embora seja relatada poliúria e polidipsia entre as alterações clínicas mais frequentes (HAGMAN et al., 2009; EVANGELISTA et al., 2011), o caso descrito não apresentava tais sinais, indo de encontro ao mencionado por DAVIDSON (2015). Embora constantemente seja observada temperatura dentro dos padrões de normalidade em casos de piometra, neste estudo o animal apresentou hipertermia $\left(40,2^{\circ} \mathrm{C}\right)$, provavelmente em decorrência do elevado grau de contaminação (DAVIDSON, 2015). O exame ultrassonográfico confirmou a suspeita inicial de piometra através dos achados clássicos de aumento de volume uterino e espessura de parede, irregularidade de contornos e áreas septadas anecóicas preenchendo o lúmen uterino, característica ultrassonográfica do acúmulo de material purulento (HEDLUND, 2008; SILVA et al., 2014). As demais anomalias presentes no caso não foram evidenciadas ao exame ultrassonográfico, presumivelmente devido às alterações topográficas causadas pela distensão uterina importante.

A piometra pode ser classificada como aberta ou fechada dependendo do grau de abertura do óstio cervical. Os sinais clínicos revelados, principalmente a secreção vaginal, caracterizam uma piometra aberta e são compatíveis com um estudo no qual $62,5 \%$ das gatas com piometra avaliadas possuíam abertura cervical (EVANGELISTA et al., 2011).

A alteração hematológica mais evidente foi a leucocitose por neutrofilia com desvio à esquerda $\left(50,4 \times 10^{3} \mu / L\right)$, monocitose e presença de neutrófilos tóxicos, sendo estas as anormalidades que ocorrem com mais frequência em quadros de piometra (HEDLUND, 2008; HAGMAN et al., 2009; EVANGELISTA et al., 2011; SILVA et al., 2014; DAVIDSON, 2015). Todavia, na piometra aberta pode ser comum a contagem de leucócitos dentro do padrão de normalidade (HEDLUND, 2008). A série vermelha do hemograma não evidenciou nenhuma alteração significativa, apenas foi observado aumento de proteínas totais no plasma, provavelmente devido à desidratação patente no animal e ao aumento de globulinas. A anemia normocítica e normocrômica é um achado habitual, principalmente em cadelas, em decorrência da toxicidade na medula óssea provocada pela inflamação, diapedese de hemácias para o lúmen uterino e depleção de ferro (HEDLUND, 2008); porém o caso relatado não possuía tal anormalidade, concordando com estudos prévios das alterações hematológicas provocadas pela piometra em felinos (HAGMAN et al., 2009; EVANGELISTA et al., 2011).

O exame bioquímico revelou aumento moderado da concentração de ureia sérica $(75 \mathrm{mg} / \mathrm{dL})$ e nível de creatinina dentro da normalidade $(1,1 \mathrm{mg} / \mathrm{dL})$. Estes achados reforçam os resultados de um estudo com oito casos de piometra felina, no qual houve aumento de ureia e os níveis de creatinina se mantiveram normais em $100 \%$ dos casos (EVANGELISTA et al., 2011). Tal achado indica que a função renal não foi afetada significantemente, posto que a creatinina, considerada o marcador mais fidedigno da taxa de filtração glomerular, permaneceu dentro dos níveis de normalidade (CARVALHO, 2015). Em gatas, antagonicamente ao que ocorre em cadelas, a injúria renal não é uma complicação habitual da piometra (HAGMAN et al., 2009; DAVIDSON, 2015). A uremia ou azotemia pré-renal é usual (DAVIDSON, 2015) e justificada provavelmente pela desidratação e fraca perfusão ou, ainda, pelo choque sistêmico (HEDLUND, 2008). 
A disfunções hepáticas são consequências comuns em animais com piometra. Acontecem em decorrência de retenção de pigmentos biliares, sepse/endotoxemia, fraca perfusão do fígado e colestase intra-hepática (HEDLUND, 2008). As anormalidades mais citadas são: elevação discreta da fosfatase alcalina (FA) e alanina aminotransferase (ALT) (DAVIDSON, 2015), hipoalbuminemia (HAGMAN et al., 2009), hiperproteinemia e hiperglobulinemia (HEDLUND, 2008). A análise da função hepática neste caso apontou hiperproteinemia $(8,8 \mathrm{~g} / \mathrm{dL})$ e hiperglobulinemia $(6,1 \mathrm{~g} / \mathrm{dL})$ conforme o referido pela literatura, e aumento leve de glutamil transferase (GGT - 7,1UI/L) - já relatado em cadelas (SILVA et al., 2014). A elevação da GGT é um parâmetro indicativo de colestase quando em associação à hiperbilirrubinemia e a níveis elevados de fosfatase alcalina (FA), o que não ocorreu neste caso (SILVA, 2015).

De acordo com parâmetros clínicos como frequência cardíaca, temperatura, respiração e contagem de leucócitos, pode ser estabelecido o diagnóstico de síndrome da resposta inflamatória sistêmica (SIRS), fator que está associado à gravidade do quadro e a altas taxas de mortalidade (HEDLUND, 2008; HAGMAN et al., 2009). No atual relato, a paciente apresentava contagem de leucócitos elevada $\left(50,4 \times 10^{3} \mu / L\right)$ e hipertermia $\left(40,2^{\circ} \mathrm{C}\right)$, o que a inclui entre os portadores de SIRS e reforça os resultados de um estudo no qual $86 \%$ das gatas com piometra eram SIRS positivo (HAGMAN et al., 2009).

O tratamento para a piometra pode ser conservativo ou cirúrgico, entretanto o tratamento clínico pode não ser eficaz e não deve ser realizado em pacientes com alterações sistêmicas importantes, sendo nesses casos a OSH a única alternativa terapêutica (HEDLUND, 2008; DAVIDSON, 2015). Dadas as alterações clínicas evidentes do caso em questão, a OSH foi a conduta escolhida para tratamento.

Durante a intervenção cirúrgica, verificou-se a ausência do corno uterino esquerdo. Em seu lugar, havia uma faixa de tecido fibroso conectado cranialmente ao ovário ipsilateral e caudalmente ao corpo do útero, caracterizando a aplasia unilateral de corno uterino (VINCE et al., 2011). Aplasias do sistema genital feminino em gatos são raras, contudo são mais comumente observadas em felinos do que em caninos (MCINTYRE et al., 2010) e todas as raças são passíveis de tais anormalidades (AGUIRRA et al., 2014).

Usualmente, podem estar associadas a hidrometra, mucometra, complexo endometrial/cístico ou piometra, como ocorrido neste relato (SCHULMANA \& BOLTONB, 1997; OH et al., 2005). A atividade cíclica geralmente está preservada, visto que os ovários possuem origem embriológica distinta (VINCE et al., 2011; AGUIRRA et al., 2014); em consonância com estes dados, os ovários apresentavam-se funcionais e inalterados anatomicamente. As aplasias uterinas isoladas não produzem sinais clínicos, constituindo um achado acidental em laparotomias exploratórias, necropsias ou ovariosalpingohisterectomias eletivas ou curativas, este último condizente com o caso em questão (CHANG, 2008; MCINTYRE, 2010; AGUIRRA et al., 2014).

Além disso, os rins não apresentavam anormalidades anatômicas, diferente do citado por CHANG et al. (2008) que constataram agenesia renal associada a aplasia uterina ipsilateral, fundamentada no desenvolvimento sincrônico e dada a mesma origem durante a organogênese entre os sistemas urinário e reprodutivo.

Durante análise macroscópica da peça cirúrgica removida (útero com aplasia unilateral de corno esquerdo e ovários - Figura 4) notou-se a presença de uma estrutura cística preenchida por conteúdo aquoso situado em mesovário, isto é, ligamento entre ovário e tuba uterina, contra-lateral à aplasia unilateral de corno 
uterino. Baseado em suas características, tal estrutura foi identificada como cisto parovariano (JAIN et al., 2012; KIM et al., 2011; KATKE, 2013).

Os cistos parovarianos em cães constituem poucos relatos na literatura, enquanto em gatos ainda não foram descritos (KIM et al., 2011; JAIN et al., 2012); por conseguinte os sinais clínicos inerentes à esta patologia carecem de maiores esclarecimentos (KIM et al., 2011). De acordo com o observado no caso em questão, os ovários não apresentaram alterações e os sinais apresentados pelo animal são justificados pelo quadro de piometra associado, reforçando a ideia de que cistos parovarianos possuem pouca relevância do ponto de vista clínico (JAIN et al., 2012).

Embora rara, a piometra deve ser incluída nos diagnósticos diferenciais de alterações reprodutivas e sistêmicas em fêmeas felinas não castradas; para tanto a anamnese tem valor importante por trazer informações relevantes como o uso de anticoncepcionais de forma indiscriminada. A aplasia unilateral de corno uterino, assim como o cisto parovariano, são anormalidades diagnosticadas por procedimentos invasivos ou exames de imagem específicos, entretanto não são relatados sinais clínicos inerentes a estas patologias, exceto infertilidade em caso de aplasia bilateral de corno uterino (VINCE et al., 2011), ou alterações da função renal por agenesia ipsilateral do rim (CHANG et al., 2008; MCINTYRE, 2010). Neste caso, o diagnóstico ocorreu devido a intervenção cirúrgica para resolução da piometra.

\section{CONCLUSÃO}

Em virtude da incomum ocorrência destas afecções, especialmente em associação no mesmo animal, este relato é o primeiro a descrever um caso de aplasia unilateral de corno uterino esquerdo associada à piometra e cisto parovariano em mesovário direito, sendo a intervenção cirúrgica e o tratamento pósoperatório eficientes para promover a resolução destas enfermidades e reestabelecimento da saúde do paciente.

\section{REFERÊNCIAS}

AGUIRRA, L. R. V. M.; PEREIRA, W. L. A.; MONGER, S. G. B.; MOREIRA, L. F. M. Aplasia de corno uterino em cadelas. Revista Brasileira de Medicina Veterinária. v. 3, n. 4, p. 351-354, 2014.

ALMEIDA, M. V. D.; REZENDE, E. P.; LAMOUNIE, A. R.; RACHID, M. A.; NASCIMENTO, E. F.; SANTOS, R. L.; VALLE, G. R. Aplasia segmentar de corpo uterino em cadela sem raça definida: relato de caso. Arquivo Brasileiro de Medicina Veterinária e Zootecnia. v. 62, n. 4, p. 797-800, 2010.

AIELLO, S. E.; MAYS A. Doenças Reprodutivas de Pequenos Animais Fêmeas. In: Manual Merck de Veterinária, São Paulo: Roca, p.855-857, 2001.

CHANG, J.; JUNG, J.; YOON, J.; CHOI, M.; PARK, J. H.; SEO, K.; JEONG, S. M. Segmental aplasia of the uterine horn with ipsilateral renal agenesis in a cat. Journal of Veterinary Medical Science. v. 70, p. 641-643, 2008.

CARVALHO, M. B. Insuficiência renal aguda. In: JERICÓ, M. M.; DE ANDRADE NETO, J. P.; KOGIKA, M. M. Tratado de medicina interna de cães e gatos. 1. ed., Rio de Janeiro: Guanabara Koogan, p. 1064 - 1094, 2015. 
EVANGELISTA, L. S. M.; QUESSADA, A. M.; LOPES, R. R. F. B.; ALVES, R. P. A.; GONÇALVES, L. M. F.; DRUMOND, K. O. Perfil clínico e laboratorial de gatas com piometra antes e após ovário-histerectomia. Revista Brasileira de Reprodução Animal. v. 35, n. 3, p. 347-351, 2011.

FELDMAN, E. C.; NELSON, R. W. Diagnosis and treatment alternatives for piometra in dogs and cats. Current Veterinary Therapy Small Animal Practice. v. 10, p. 1305- 1310, 1989.

GRADELA, A.; MACEDO, A. G. C. M.; DE MATOS, M. H. T.; DE LIMA, R. S.; FRANZO, V. S. Defeitos congênitos raros associados à hérnia de Morgagni e à aplasia segmentar de corno uterino em cadela: Relato de caso. Semina: Ciências Agrárias. v. 34, n. 4, p. 1841-1850, 2013.

GREEN, S. L.; TOLWANI, R. J.; WAGGIED, K.S.; OTTO, G.M. Endometriosis and a paraovarian cyst in a rhesus macaque. Veterinary Radiology \& Ultrasound. v. 40, n. 3, p. 271-274, 1999.

HAGMAN, R.; KARLSTAM, E.; PERSSON, S.; KINDAHL, H. Plasma PGF $2 \alpha$ metabolite levels in cats with uterine disease. Theriogenology. v. 72, p. 1180-1187, 2009.

HEDLUND, C. S. Cirurgias dos sistemas reprodutivos e genital. In: FOSSUM, T.W. Cirurgia de pequenos animais. 3. ed., Mosby - Elsevier, p.737-743, 2008.

JAIN, H. T.; UPADHYE, S. V., DHOOT, V. M., KHANTE, G., CHIPDE, V. D. Pyometra with ovarian and parovarian cysts in german shepherd bitch- a case report. Indian Journal Of Canine Practice. v. 4, n. 1, 2012.

KATKE, R. D.; PAGARE, P.; RAINA, J.; SINGH, K. A rare case of successful pregnancy outcome with giant paraovarian cyst: a case report and review of literature. International Journal of Reproduction, Contraception, Obstetrics and Gynecology. v. 2, n. 4, p. 730-732, 2013.

KIM, H.; CHOI, H.; KIM,. H.; CHOI, J. A Giant Parovarian Cyst in a Dog with a Granulosa Cell tumor. Journal of Veterinary Medical Science. v. 74, n. 3, p. 385 389, 2011.

MCINTYRE, R. L.; LEVY, J.K.; ROBERTS, J. F.; REEP, R.L. Developmental uterine anomalies in cats and dogs undergoing elective ovariohysterectomy. Journal of the American Veterinary Medical Association. v. 237, n. 5, p. 542-546, 2010.

DAVIDSON, A. P. Distúrbios do sistema reprodutor. In: NELSON, R.W.; COUTO, C.G. Medicina Interna de Pequenos Animais. 5. ed. Rio de Janeiro: Elsevier, 2015, p. $952-955.2015$.

OH, K., SON, C.; KIM, B.; HWANG, S.; KIM, Y.; PARK, S.; JEONG, J.; JEONG, C.; PARK, S.; CHO, K. Segmental aplasia of uterine body in an adult mixed breed dog. Journal of Veterinary Diagnostic Investigation. v. 17, p. 490-492, 2005. 
SCHULMANA, M. L.; BOLTONB, L. A. Uterine horn aplasia with complications in two mixed-breed bitches. Journal of the South African Veterinary Association. v. 68, n. 4, p. 150-153, 1997.

SILVA, L. F. M. C.; OLIVEIRA, S. N.; DALANEZI, F. M.; ARAUJO, E. A. B.; ZAHN, F. S.; PRESTES, N. C. Histerocele inguinal em cadela com piometra - relato de caso. Clínica Veterinária (São Paulo). v. 110, p. 56-61, 2014.

SILVA, R. D. Avaliação laboratorial do sistema hepatobiliar. In: JERICÓ, M.M.; DE ANDRADE NETO, J.P.; KOGIKA, M.M. Tratado de medicina interna de cães e gatos. 1. ed., Rio de Janeiro: Guanabara Koogan, p. 1030 - 1035, 2015.

STONE, E. A. Ovário e útero. In: Slatter D. Manual de cirurgia de pequenos animais. 3. ed., São Paulo: Manole, v.2, p.1487-1502, 2007.

VINCE, S. V. S.;ŽEVRNJA, B.; BECK, A.; FOLNOŽIĆ, I.; GEREŠ, D.; SAMARDŽIJA, M.; GRIZELJ, J.; DOBRANIĆ, T. Unilateral segmental aplasia of the uterine horn in a gravid bitch Unilateral segmental aplasia of the uterine horn in a gravid bitch - a case report. Veterinarski Arhiv. v. 81, n. 5, p. 691-698, 2011.

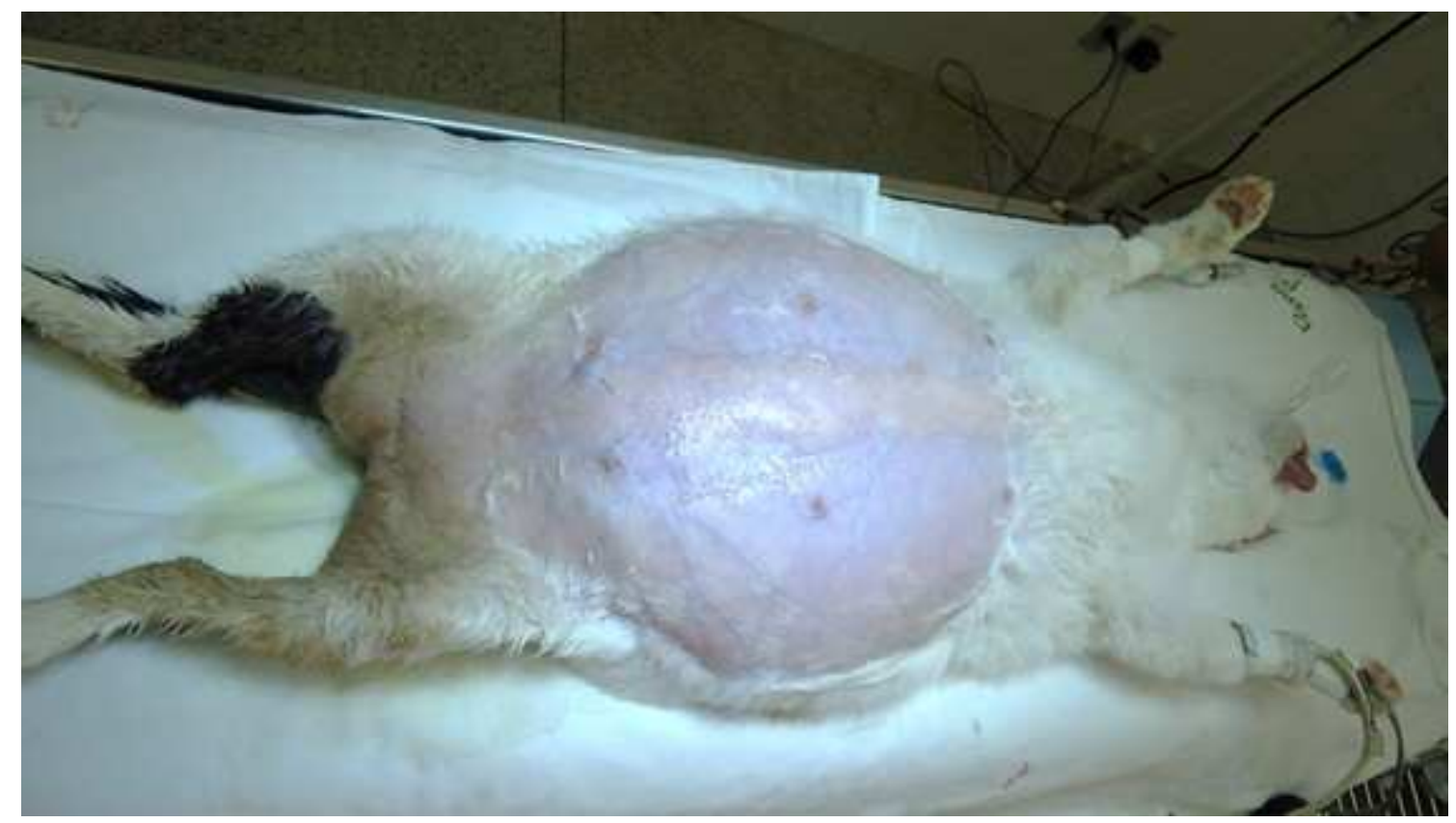

FIGURA 1 Distensão abdominal evidente em animal no momento pré-operatório. Fonte: Elaboração dos Autores 


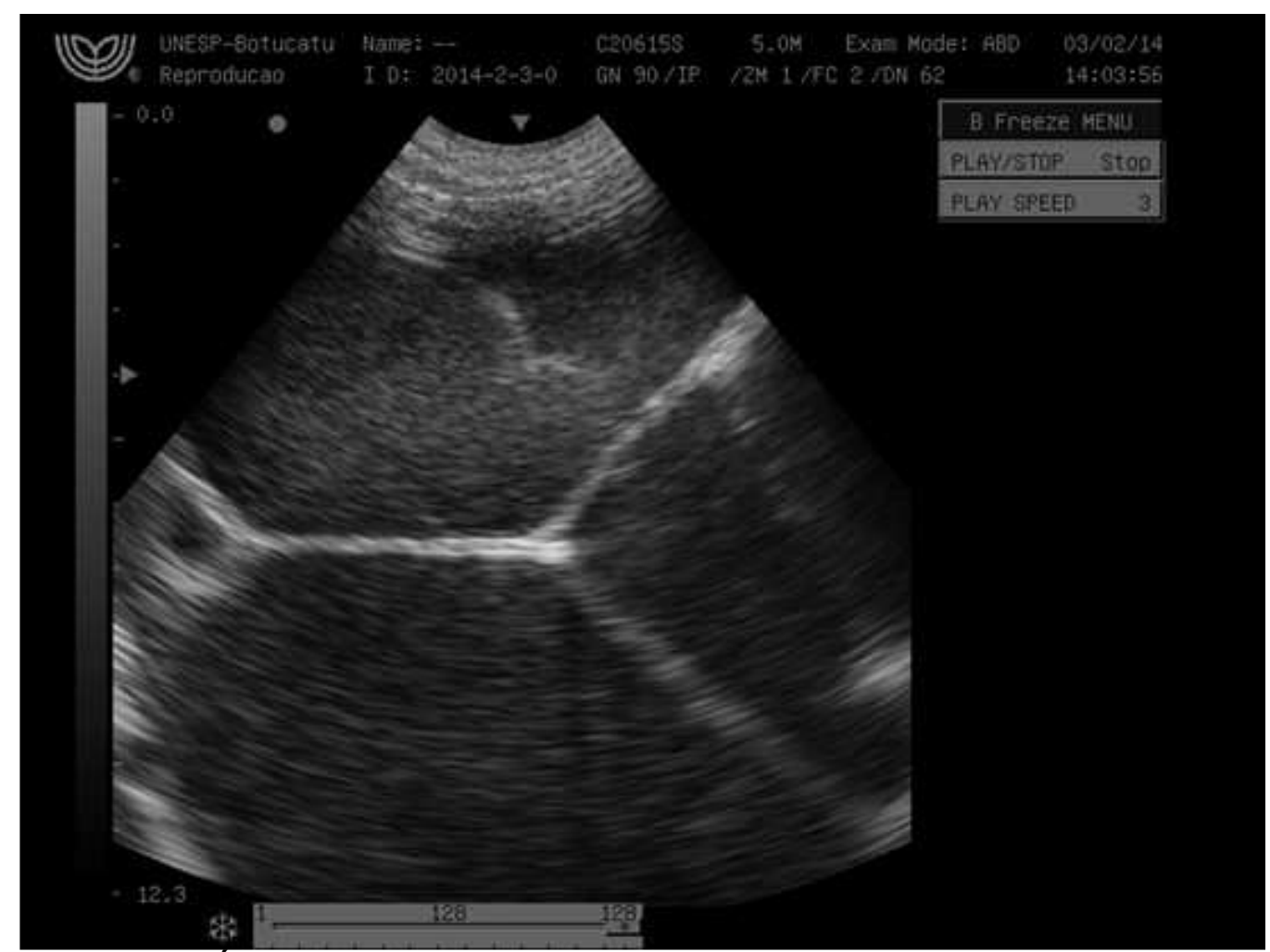

FIGURA 2 Áreas lobuladas com regiões anecóicas caracterizando acúmulo de material no ambiente uterino.

Fonte: Elaboração dos Autores

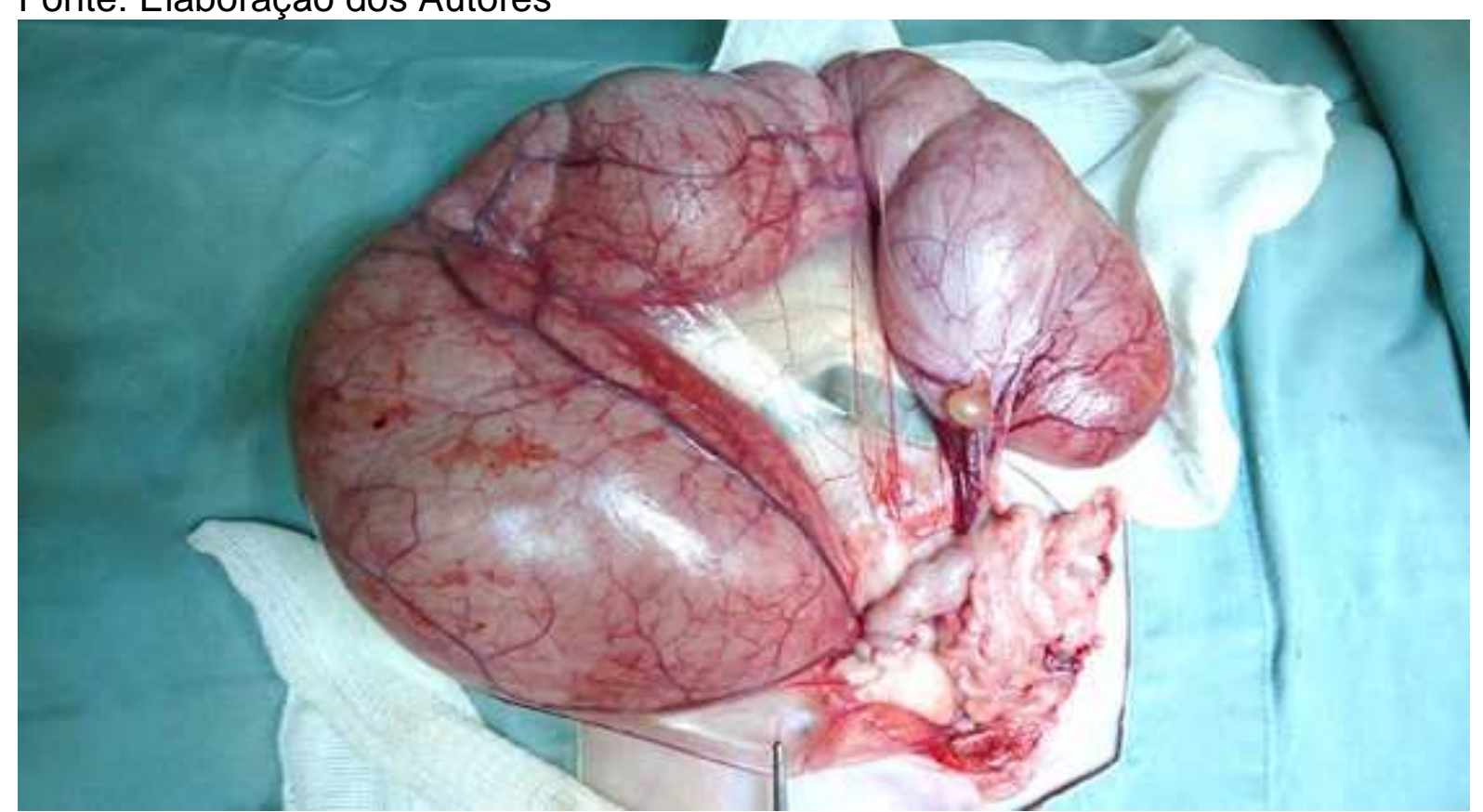

FIGURA 3 Exposição dos cornos uterinos, demonstrando a aplasia unilateral de corno uterino esquerdo.

Fonte: Elaboração dos Autores 


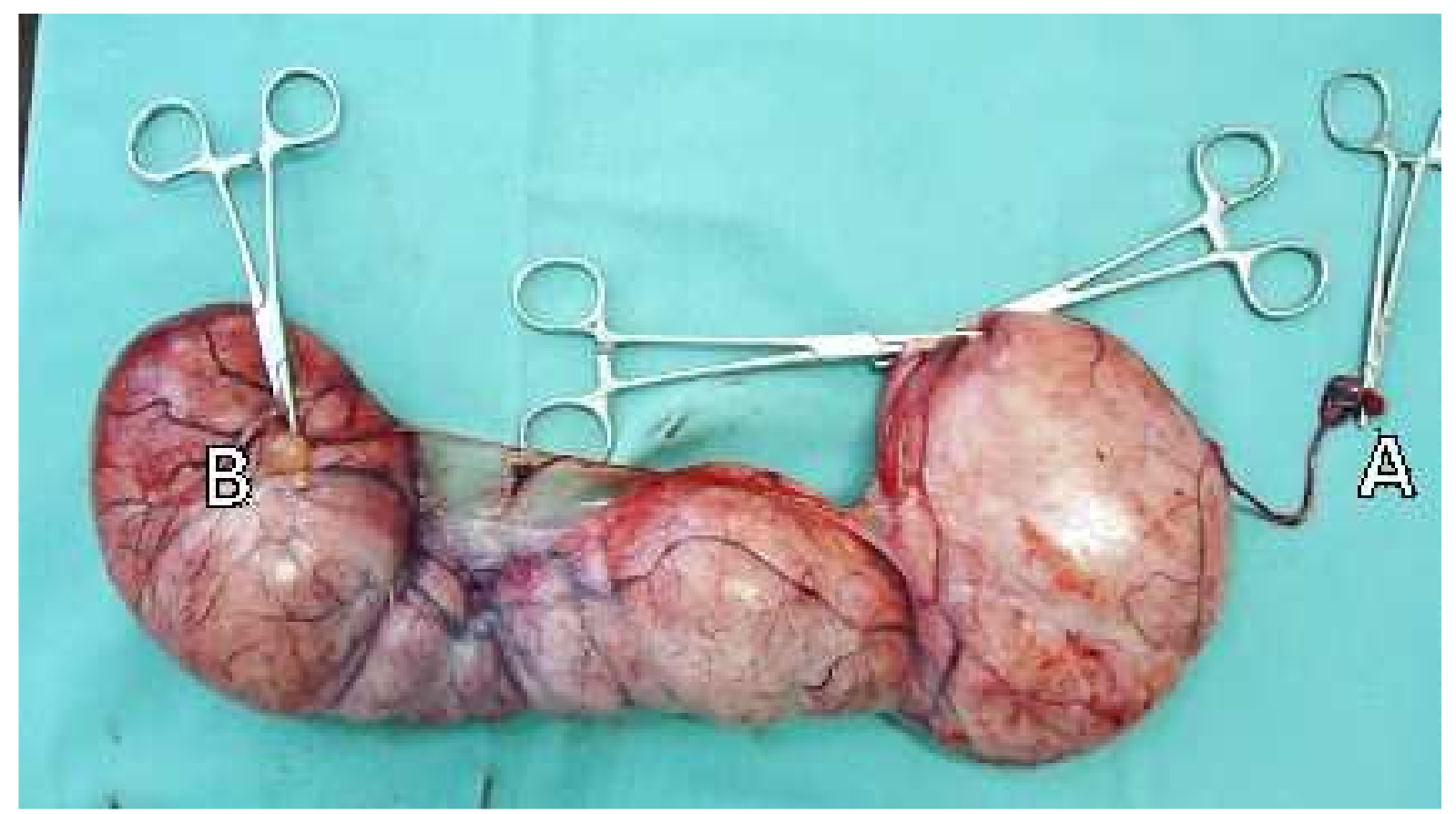

FIGURA 4 Aplasia unilateral de corno uterino esquerdo $(A)$ e cisto parovariano em mesovario direito (B).

Fonte: Elaboração dos Autores 